\title{
Methyl Mercury Exposure at Niigata, Japan: Results of Neurological Examinations of 103 Adults
}

\author{
Kimio Maruyama, ${ }^{1}$ Takashi Yorifuji, ${ }^{2}$ Toshihide Tsuda, ${ }^{2}$ Tomoko Sekikawa, ${ }^{3}$ \\ Hiroto Nakadaira, ${ }^{4}$ and Hisashi Saito ${ }^{5}$ \\ ${ }^{1}$ Department of Social Welfare and Psychology, Faculty of Nursing, Social Welfare and Psychology, Niigata Seiryo University, \\ 1-5939 Suido-cho, Chuo-ku, Niigata 951-8121, Japan \\ ${ }^{2}$ Department of Human Ecology, Okayama University Graduate School of Environmental and Life Science, 3-1-1 Tsushima-naka, \\ Kita-ku, Okayama 700-8530, Japan \\ ${ }^{3}$ Department of Internal Medicine, Nuttari Clinic, 6-4-12 Nuttarihigasi, Chuo-ku, Niigata 950-0075, Japan \\ ${ }^{4}$ Department of Nursing, Faculty of Nursing, Social Welfare and Psychology, Niigata Seiryo University, 1-5939 Suido-cho, \\ Chuo-ku, Niigata 951-8121, Japan \\ ${ }^{5}$ Department of Internal Medicine, Kido Hospital, 4-13-3 Takeo, Higashi-ku, Niigata 950-0862, Japan
}

Correspondence should be addressed to Kimio Maruyama, k-maruyama@n-seiryo.ac.jp

Received 6 April 2012; Revised 2 June 2012; Accepted 8 June 2012

Academic Editor: Jose G. Dorea

Copyright () 2012 Kimio Maruyama et al. This is an open access article distributed under the Creative Commons Attribution License, which permits unrestricted use, distribution, and reproduction in any medium, provided the original work is properly cited.

\begin{abstract}
Background. Large-scale poisonings caused by methyl mercury (MeHg) have occurred in Japan (Minamata in the 1950s and Niigata in the 1960s) and Iraq (in the 1970s). The current WHO neurological risk standard for adult exposure (hair level: $50 \mu \mathrm{g} / \mathrm{g}$ ) was based partly on evidence from Niigata which did not consider any cases who were diagnosed later and/or exposed to low level of $\mathrm{MeHg}$ (hair mercury level less than $50 \mu \mathrm{g} / \mathrm{g}$ ). Methods. Early in the Niigata epidemic in June 1965 there were two extensive surveys. From these two surveys, we examined 103 adults with hair mercury measurement who consulted two medical institutions. We compared the prevalence and the distribution of neurological signs related to $\mathrm{MeHg}$ poisoning between exposure categories. Result. We found 48 subjects with neurological signs related to MeHg poisoning who had hair mercury concentration less than $50 \mu \mathrm{g} / \mathrm{g}$. Among the neurological signs, sensory disturbance of the bilateral distal extremities was observed more frequently, followed by disequilibrium, hearing impairment, and ataxia, in groups with hair $\mathrm{MeHg}$ concentration both below $50 \mu \mathrm{g} / \mathrm{g}$ and over $50 \mu \mathrm{g} / \mathrm{g}$. Conclusion. The present study suggests the possibility that exposure to $\mathrm{MeHg}$ at levels below the current WHO limits could cause neurologic signs, in particular, sensory disturbance.
\end{abstract}

\section{Introduction}

Large-scale poisonings caused by methyl mercury ( $\mathrm{MeHg}$ ) have occurred in Japan (Minamata in the 1950s and Niigata in the 1960s) and Iraq (in the 1970s) [1-3]. These poisonings provided substantial data regarding the neurologic signs caused by MeHg: sensory disturbance, ataxia, constriction of the visual field, speech disturbance, and hearing impairment [1-7]. In Minamata, the etiologic agent $(\mathrm{MeHg})$ was not acknowledged until three years after official identification of the exposed cases (in 1956); thus, there were few attempts to evaluate the association between $\mathrm{MeHg}$ exposure and neurologic signs (i.e., dose-response relationships). In contrast, in the settings of Niigata and Iraq, $\mathrm{MeHg}$ was recognized as an etiologic agent in the early phase of the poisonings $[1,5,7]$, which provided the occasions to examine the dose-response relationships. The findings from these two poisonings therefore provided significant insights for World Health Organization (WHO) conclusion on mercury and health $[1,8]$.

Indeed, WHO published two reports of Environmental Health Criteria in 1976 and 1990 based on the findings from the Japanese and Iraqi outbreaks [1, 8-10]. Then, WHO concluded that "Certain groups with high fish consumption 
may attain a high blood methyl mercury level (about $200 \mu \mathrm{g} /$ liter, corresponding to $50 \mu \mathrm{g} / \mathrm{g}$ of hair) associated with a low $(5 \%)$ risk of neurological damage to adults" [9]. The reports also mentioned that "No adverse effects have been detected with long-term daily methyl mercury intakes of 3-7 $\mu \mathrm{g} / \mathrm{kg}$ body weight (hair mercury concentrations of approximately $50-125 \mu \mathrm{g} / \mathrm{g}$ )" [9]. In the process of making the conclusion, WHO reports cited publications from Niigata which mentioned that the mercury content in hair samples from 30 initial patients, officially certified as having $\mathrm{MeHg}$ poisoning, ranged from $52 \mu \mathrm{g} / \mathrm{g}$ to $570 \mu \mathrm{g} / \mathrm{g}[3,11,12]$. However, the publications did not consider any cases who were diagnosed later and/or exposed low level of $\mathrm{MeHg}$ (hair mercury level less than $50 \mu \mathrm{g} / \mathrm{g}$ ), possibly distorting the conclusion of WHO.

Early on in the Niigata poisoning in 1965, there were two extensive surveys of people living along the Agano River and the adjacent areas, which included assessment of hair mercury concentration. In the present study, we targeted 103 adults from the surveys and examined whether neurological signs related to $\mathrm{MeHg}$ exposure were observed below hair mercury concentration of $50 \mu \mathrm{g} / \mathrm{g}$ as well as the distributions of the neurological signs among the participants. Because $\mathrm{MeHg}$ exposure through fish consumption has attracted intense public health interest [13], the findings from Niigata would be valuable.

\section{Material and Methods}

2.1. Study Areas and Subjects. In Niigata Japan, the first case of $\mathrm{MeHg}$ poisoning was found in January, the second in April, and the third in May, of 1965. Seven patients were confirmed before June and all lived around the lower stream of the Agano River. Their exposure was due to consumption of fish and shellfish contaminated by $\mathrm{MeHg}$ discharged from a chemical factory (Showa Denko Kanose Factory) located on the upper reaches of the Agano River [3, 5, 6, 11, 12, 14]. The total mercury content of fish samples collected in June 1965 from the Agano River was elevated (barbel, 21.0 23.6 ppm; snakehead mullet, $12.3 \mathrm{ppm}$; chub, $4.6 \sim 8.38 \mathrm{ppm}$ ) and one eel captured near Tsugawa town (a town along the Agano River) had 41.0 ppm [7].

In June 1965, two surveys were carried out for all officially registered inhabitants of five administrative districts located within $15 \mathrm{~km}$ from the mouth of the river where the seven patients lived. The administrative districts were composed of the parts of 2 cities, 2 towns, and one village, consisting of 65 settlements. The first survey was conducted in 6 settlements where the first 7 patients lived between June 14, 1965 and June 18,1965 by medical doctors, interns, and students from the Niigata University Medical Department. The second survey was performed between June 21, 1965 and June 24, 1965 by the Niigata Prefecture Sanitation Department in the remaining 59 settlements of the districts. The second survey included public health nurses from the prefectural health centers as well $[5,7,15]$.

The sampling process of the study subjects from these two surveys is shown in Figure 1. In the first survey, 2,813 inhabitants were interviewed using a standardized questionnaire to determine the extent of their $\mathrm{MeHg}$ exposure. The survey focused on symptoms related to $\mathrm{MeHg}$ exposure and river fish consumption. Subjects with symptoms suggestive of $\mathrm{MeHg}$ exposure were subsequently examined neurologically. The second survey was done in the same fashion on 19,888 inhabitants of the lower reaches of the Agano River basin.

From these interviews, 1,386 persons were identified as being exposed because they had symptoms or findings suggestive of $\mathrm{MeHg}$ exposure; because other family members had symptoms related to $\mathrm{MeHg}$ poisoning; or because they consumed river fish in large quantities. Subsequently, their total hair mercury concentration was measured $[5,7]$. After that, in July 1965, Niigata Prefecture restricted the taking of fish and shellfish on the lower reaches of the Agano River.

Among 1,386 persons, 109 subjects who had symptoms related to $\mathrm{MeHg}$ poisoning as chief complaints voluntarily consulted at either (or both) of two medical institutions (Nuttari clinic and Kido hospital) for medical care for the first time during the period of 1965 to 1986 . The two institutions are medical institutions which have followed $\mathrm{MeHg}$ poisoning cases in Niigata just after the outbreak in 1965, cooperating with Niigata University. Most of the patients still consult at either (or both) of the two medical institutions for medical care. In the present study, we included 103 adults ( $\geqq 20$ years old) and considered the neurological manifestations observed at their first consultation.

2.2. Measurement of $\mathrm{MeHg}$ in Hair. The subjects had their hair collected before the restriction of fish and shellfish (in July 1965) and were believed to be consuming the contaminated fish and shellfish when mercury was measured. The mercury content of hair samples was measured using 3 different techniques: the Dithizone method, Neutron Activation Analysis, and Atomic Absorption Spectroscopy at the Niigata University $[5,7]$. We report the values without any interpolation.

\subsection{Measurement of Outcomes (Diagnosis of Neurological} Signs from $\mathrm{MeHg}$ Exposure). The 103 subjects were evaluated using a standard neurological examination by at least two well-trained physicians including two of the authors in the present study (T. Sekikawa and H. Saito) between 1965 and 1986. In particular, one of the authors (H. Saito) has been treating the $\mathrm{MeHg}$ poisoning cases since the outbreak in 1965 at the two medical institutions up to the present and was involved in all of the neurological examinations. Thus, neurological examination was standardized over the study period and between the examiners. Data were collected on neurological signs related to $\mathrm{MeHg}$ poisoning, namely, sensory disturbance of the distal extremities, perioral area, and whole body; ataxia; visual constriction; hearing impairment; speech disturbance; disequilibrium. However, not all subjects underwent all neurological tests: data on whole body sensory disturbance, visual constriction, hearing impairment, speech disturbance, and disequilibrium were missing for $7,8,9$, 7, 1 study subjects, respectively. In the previous study in 


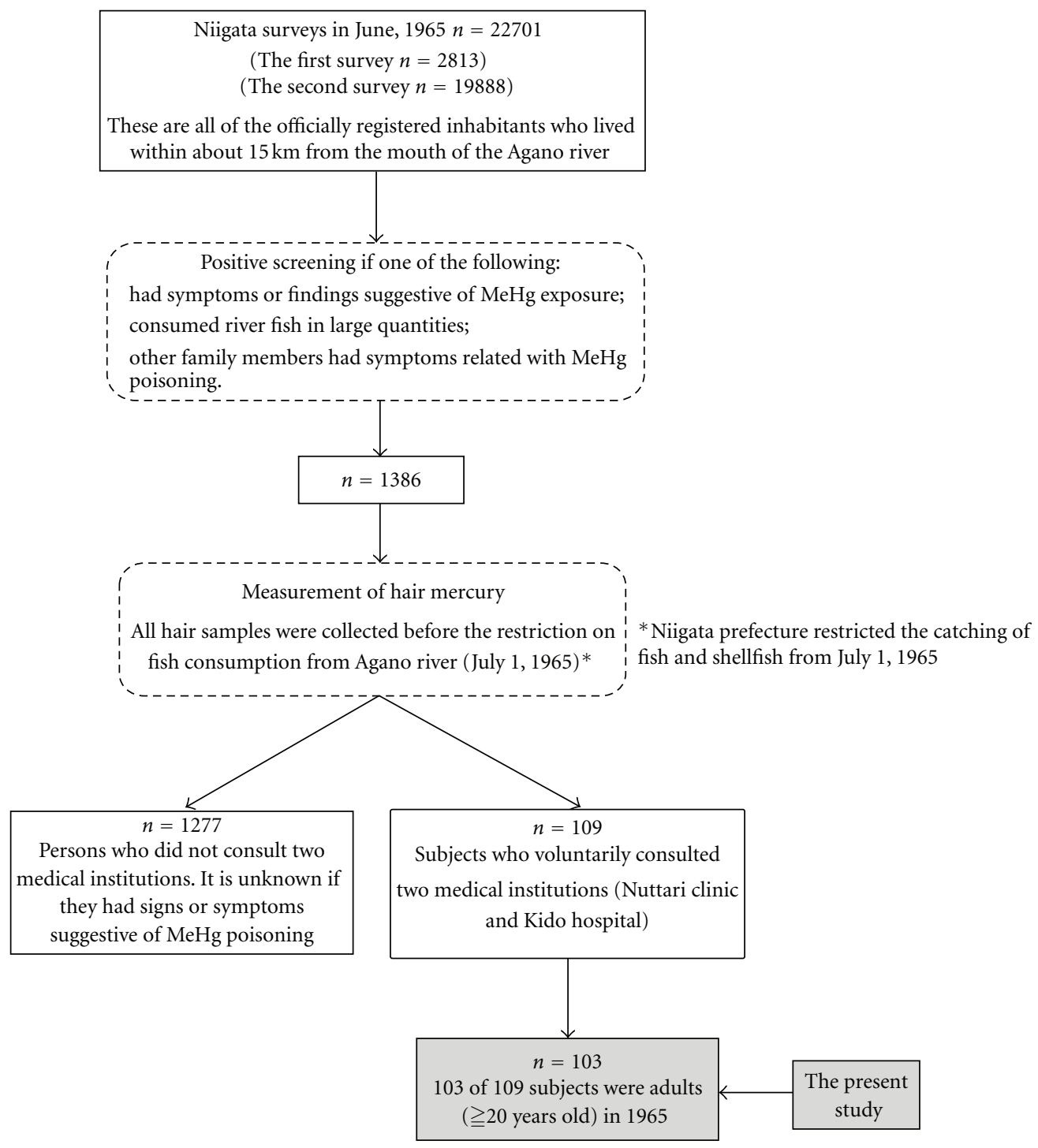

FIGURE 1: Sampling process of the study subjects.

Minamata, it was noted that sensory disturbance of the bilateral distal extremities could be used as the gold standard for the diagnosis of Minamata Disease (methyl mercury poisoning-related neurological disorders) in the exposed areas $[16,17]$.

Tactile sensation was estimated using a small paint brush and pain sensation was tested using a roulette wheel. Visual fields were examined by confrontation. Hearing impairment was examined by tuning fork of $512 \mathrm{~Hz}$ and a ticking watch. Speech disturbances were examined by phonation of labial and lingual sounds. Ataxia was determined by 3 tests; Adiadochokinesis, Finger-Nose, and Heel-Knee. Disequilibrium was tested by 3 tests; Romberg test, Mann test, and standing on one foot. Mann test is used to investigate the loss of motor coordination. The procedure is as follows: the subject stands with both legs on a straight line putting one toenail behind the heel of the other foot and looks straight ahead with eyes open and then closes both eyes. The subject repeats the procedure reversing the positions of his feet. Mann test is judged positive when the subject sways. For ataxia and disequilibrium, each test was scored as positive $(+)$, equivocal $( \pm)$, or negative $(-)$. If one test in the group was positive that category was classified as positive. If there were no positives in the three tests and there was one and over $( \pm)$ in the category it was scored as equivocal. When all 3 tests were negative, the category was classified as negative. When the categories were classified as positive or equivocal, ataxia and disequilibrium are scored positive in this study. The subjects were all examined between June 1965 and July 1986. In the present study, we examined neurological symptoms and signs at the first consultation for the two medical institutions (i.e., the closest findings to the hair mercury measurement of June, 1965).

\section{Analysis}

First, we described the demographic characteristics of the subjects by exposure category $(0-\leq 20 \mu \mathrm{g} / \mathrm{g}, 20-50 \mu \mathrm{g} / \mathrm{g}$, 
$50-100 \mu \mathrm{g} / \mathrm{g}$, and $>100 \mu \mathrm{g} / \mathrm{g})$. We then compared the prevalence proportions of neurological signs between the exposure categories. We estimated the adjusted prevalence odds ratios of exposure using a logistic regression model, employing the lowest measured category as reference. We adjusted for age and sex. We also conducted statistical tests for trend. In a sensitivity analysis, we restricted the subjects whose hair mercury concentration was measured by the Dithizone method, which the previous publications from Niigata adopted, and repeated the same analysis. All confidence intervals were calculated at the 95\% level. PASW software version 18.0 was used for all analyses.

\section{Results}

The distribution of the 103 subjects among 1,386 persons (who were measured mercury concentration) separated by the exposure category is shown in Table 1. The persons who had lower level of mercury concentration in hair tended not to be consulted at the medical institutions. The characteristics of the study subjects separated by the exposure category are also shown in Table 2 . The subjects in the highest exposure category ( $>100 \mu \mathrm{g} / \mathrm{g}$ ) tended to be younger in 1965, men, and examined earlier after their signs appeared. About seven-tenths of the samples $(69.9 \%)$ were measured using the Dithizone method, while about one-fourth $(25.2 \%)$ by Neutron Activation Analysis, and only 5 samples (4.9\%) by Atomic Absorption Spectroscopy.

Figure 2 and Table 3 show the frequency of neurological signs related to $\mathrm{MeHg}$ poisoning separated by the hair mercury content group. Distal sensory disturbance of the bilateral extremities was most frequently detected (95.1\%), followed by disequilibrium $(86.3 \%)$, hearing impairment (75.5\%), and ataxia (70.9\%). Half of the subjects manifested sensory disturbance of the perioral area (57.3\%) and visual constriction $(44.2 \%)$. All of the subjects who had a perioral sensory disturbance had a sensory disturbance of the bilateral extremities. Even the subjects who had hair mercury levels less than $50 \mu \mathrm{g} / \mathrm{g}$ had a variety of neurological signs related to $\mathrm{MeHg}$ poisoning.

When we estimated the adjusted prevalence odds ratios (Table 3), the associations between exposure and neurological signs were not apparent because neurological sings were detected even in the low exposure categories. Statistical doseresponse relationships were not apparent except perioral sensory disturbance $(P=0.04)$.

Even when we restricted the subjects whose hair mercury concentration was measured by the Dithizone method, the 28 subjects (Table 2) with hair mercury concentration less than $50 \mu \mathrm{g} / \mathrm{g}$ had the neurological signs related to $\mathrm{MeHg}$ poisoning.

\section{Discussion}

In the present study, we examined whether neurological signs related to $\mathrm{MeHg}$ exposure were observed below hair mercury concentration of $50 \mu \mathrm{g} / \mathrm{g}$ as well as the distributions of the neurological signs in Niigata, Japan. We then found that there were the 48 subjects with hair mercury concentration less than $50 \mu \mathrm{g} / \mathrm{g}$ had the neurological signs related to $\mathrm{MeHg}$ poisoning, that is, some of the subjects with the typical neurological signs had hair mercury levels less than $50 \mu \mathrm{g} / \mathrm{g}$. Moreover, among the neurological signs, sensory disturbance of the bilateral distal extremities, disequilibrium, hearing impairment, and ataxia were observed more frequently.

Although the previous studies conducted in the same exposed area (Niigata) suggested that the hair mercury content from the initial patients ranged from $52 \mu \mathrm{g} / \mathrm{g}$ to $570 \mu \mathrm{g} / \mathrm{g}[11,12,14]$, the present study provided an additional finding that the subjects who had similar neurological signs were detected even among the 48 subjects below hair mercury concentration of $50 \mu \mathrm{g} / \mathrm{g}$. Although we do not have information about the neurological signs of 48 subjects at survey time (in June 1965), they had a variety of neurological signs related to $\mathrm{MeHg}$ poisoning when we examined. This is probably because our study included the subjects who manifested the signs later and who had less severe signs in the low exposure level compared to the previous studies.

Given the sampling process of the present study (only $7.4 \%$ of the hair-mercury-measured subjects) (Figure 1 and Table 1), there may be a question about inferring that the persons who have hair mercury concentration less than $50 \mu \mathrm{g} / \mathrm{g}$ really manifest the typical neurological signs induced by $\mathrm{MeHg}$ exposure. However, the notion that persons with the low level of exposure manifest such neurological signs could be supported by the following evidence: first, the prevalence of such typical neurological signs among unexposed population is rare (e.g., prevalence of sensory disturbance of the bilateral distal extremities ranged from 0 to $1.1 \%$ [18-22]). Second, as mentioned, it was noted that sensory disturbance of the bilateral distal extremities could be used as the gold standard for the diagnosis of Minamata Disease (methyl mercury poisoning-related neurological disorders) in the exposed areas $[16,17]$. This evidence was supported by the findings that sensory disturbance had the lowest threshold [1]; milder cases only had sensory disturbance $[1,8]$; sensory disturbance was the most persistent neurologic sign [18]; the prevalence of sensory disturbance of the bilateral distal extremities was low (as mentioned). Therefore, it could be considered that the subjects in the present study who had hair mercury concentration less than $50 \mu \mathrm{g} / \mathrm{g}$ manifested the typical neurological signs because of $\mathrm{MeHg}$ exposure.

Moreover, even if we assumed that persons who did not consult at the medical institutions did not have any typical neurological signs, the prevalence of the neurological signs would be still higher than that of general population For example, 23, 23, 20, and 32 subjects had sensory disturbance of the bilateral distal extremities in each exposure category $(0-<20,20-50,50-100$, and $>100 \mu \mathrm{g} / \mathrm{g})$ (Table 3); thus, the prevalence of the neurological sign was $2.5,7.5,22.0$, and $52.5 \%$ in each category assuming that persons who did not consult at the medical institutions did not have any typical neurological signs (Table 1). The prevalence, in particular in the categories of hair mercury levels less than $50 \mu \mathrm{g} / \mathrm{g}$, is still higher than that of general population mentioned above (0 to $1.1 \%$ [18-22]). The present study therefore supports that long-term exposure to $\mathrm{MeHg}$ at levels below the current 
TABLE 1: Distribution of the 103 subjects among 1,386 persons (whose hair mercury concentrations were measured) separated by the exposure category.

\begin{tabular}{lccccc}
\hline & $\begin{array}{c}0-\leq 20 \mu \mathrm{g} / \mathrm{g} \\
(n=926)\end{array}$ & $\begin{array}{c}20-50 \mu \mathrm{g} / \mathrm{g} \\
(n=308)\end{array}$ & $\begin{array}{c}50-100 \mu \mathrm{g} / \mathrm{g} \\
(n=91)\end{array}$ & $\begin{array}{c}>100 \mu \mathrm{g} / \mathrm{g} \\
(n=61)\end{array}$ & $\begin{array}{c}\text { Total } \\
(n=1386)\end{array}$ \\
\hline $\begin{array}{l}\text { Persons who did not consult two medical institutions } \\
\text { Subjects in the present study }\end{array}$ & 901 & 283 & 67 & 1277 \\
\hline
\end{tabular}

* Number after the plus sign shows the number of persons younger than 20 years old. Consequently, 103 subjects were included in the present study. Source: Ministry of Health and Welfare.

TABLE 2: Characteristics of subjects by hair mercury content.

\begin{tabular}{|c|c|c|c|c|c|}
\hline & $\begin{array}{c}\text { All } \\
(n=103)\end{array}$ & $\begin{array}{c}0-\leq 20 \mu \mathrm{g} / \mathrm{g} \\
(n=24)\end{array}$ & $\begin{array}{c}20-50 \mu \mathrm{g} / \mathrm{g} \\
(n=24)\end{array}$ & $\begin{array}{c}50-100 \mu \mathrm{g} / \mathrm{g} \\
(n=21)\end{array}$ & $\begin{array}{c}>100 \mu \mathrm{g} / \mathrm{g} \\
(n=34)\end{array}$ \\
\hline Mean age in years $(1965) \pm S D$ & $44.5 \pm 12.9$ & $45.3 \pm 12.9$ & $44.8 \pm 12.4$ & $49.5 \pm 13.1$ & $40.6 \pm 12.4$ \\
\hline \multicolumn{6}{|l|}{ Sex } \\
\hline Men & $61(59.2 \%)$ & $11(45.8 \%)$ & $12(50.0 \%)$ & $12(57.1 \%)$ & $26(76.5 \%)$ \\
\hline Women & $42(40.8 \%)$ & $13(54.2 \%)$ & $12(50.0 \%)$ & $9(42.9 \%)$ & $8(23.5 \%)$ \\
\hline Date symptoms began & $1964-1973$ & $1964-1973$ & $1964-1970$ & $1964-1972$ & $1964-1971$ \\
\hline Mean age in years $( \pm$ SD) that symptoms began & $45.5 \pm 12.8$ & $46.0 \pm 12.8$ & $46.5 \pm 13.5$ & $51.4 \pm 13.0$ & $40.4 \pm 10.7$ \\
\hline Mean age in years of assessment of neurologic signs \pm SD & $50.7 \pm 13.0$ & $53.9 \pm 12.4$ & $52.4 \pm 12.5$ & $56.3 \pm 11.7$ & $43.6 \pm 11.7$ \\
\hline Mean hair mercury content \pm SD $(\mu \mathrm{g} / \mathrm{g})$ & $107.6 \pm 123.1$ & $13.2 \pm 4.5$ & $32.6 \pm 8.5$ & $72.6 \pm 13.9$ & $248.8 \pm 121.4$ \\
\hline Hair mercury content $(\mu \mathrm{g} / \mathrm{g})(\min -\max )$ & $4.2-570.0$ & $4.2-19.5$ & $20.5-46.6$ & $56.0-100.0$ & $104.0-570.0$ \\
\hline \multicolumn{6}{|l|}{ Analysis method of hair mercury (1965) } \\
\hline Dithizone & $72(69.9 \%)$ & $10(41.7 \%)$ & $18(75.0 \%)$ & $13(61.9 \%)$ & $31(91.2 \%)$ \\
\hline Neutron activation & $26(25.2 \%)$ & $13(54.2 \%)$ & $6(25.0 \%)$ & $5(23.8 \%)$ & $2(5.9 \%)$ \\
\hline Atomic absorption & $5(4.9 \%)$ & $1(4.1 \%)$ & $0(0 \%)$ & $3(14.3 \%)$ & $1(2.9 \%)$ \\
\hline
\end{tabular}

SD: standard deviation.

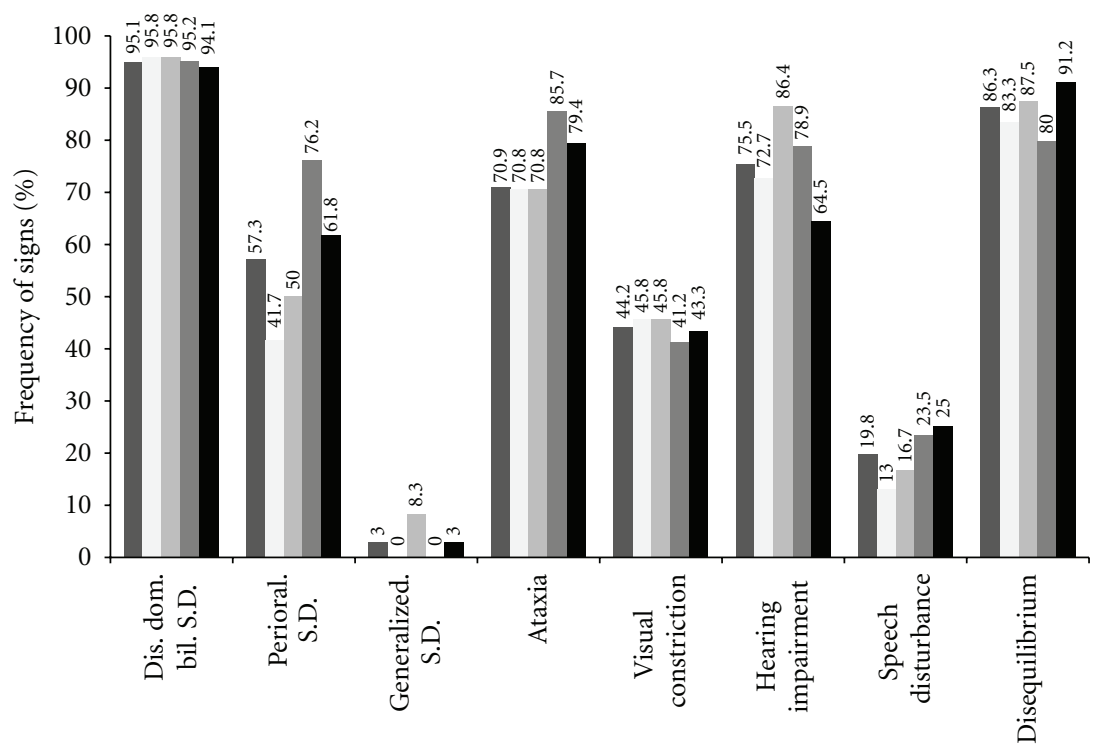

Neurological signs

$$
\begin{array}{ll}
\text { All }(n=103) & 50-100 \mu \mathrm{g} / \mathrm{g}(n=21) \\
0-\leq 20 \mu \mathrm{g} / \mathrm{g}(n=24) & \square \\
20-50 \mu \mathrm{g} / \mathrm{g}(n=24) &
\end{array}
$$

Figure 2: Hair mercury content and frequency of neurological signs. Dis.dom.bil. S.D.: distal dominant bilateral Sensory Disturbance S.D.: sensory disturbance. 
TABLE 3: Adjusted PORs* and their 95\% C.I.s between mercury content and neurological signs.

\begin{tabular}{|c|c|c|c|c|c|}
\hline & $\begin{array}{c}0-\leq 20 \mu \mathrm{g} / \mathrm{g} \\
(n=24)\end{array}$ & $\begin{array}{c}20-50 \mu \mathrm{g} / \mathrm{g} \\
(n=24)\end{array}$ & $\begin{array}{c}50-100 \mu \mathrm{g} / \mathrm{g} \\
(n=21)\end{array}$ & $\begin{array}{l}>100 \mu \mathrm{g} / \mathrm{g} \\
(n=34)\end{array}$ & $P$ value for trend \\
\hline Dis.dom.bil. S.D. $n(\%)$ & $23(95.8)$ & $23(95.8)$ & $20(95.2)$ & $32(94.1)$ & \\
\hline PORs and 95\% CIs & 1 & $1.0(0.1,18.1)$ & $0.6(0,11.7)$ & $0.7(0,10.4)$ & 0.74 \\
\hline Perioral S.D. $n(\%)$ & $10(41.7)$ & $12(50)$ & $16(76.2)$ & $21(61.8)$ & \\
\hline PORs and 95\% CIs & 1 & $1.4(0.5,4.5)$ & $4.3(1.2,16)$ & $2.7(0.9,8.3)$ & 0.04 \\
\hline Whole body S.D. $n(\%)$ & $0(0)$ & $2(8.3)$ & $0(0)$ & $1(3)$ & \\
\hline PORs and 95\% CIs & 1 & NE & $\mathrm{NE}$ & NE & 0.98 \\
\hline $\operatorname{Ataxia} n(\%)$ & $17(70.8)$ & $17(70.8)$ & $18(85.7)$ & $27(79.4)$ & \\
\hline PORs and 95\% CIs & 1 & $1.0(0.3,3.8)$ & $2.2(0.5,10.5)$ & $2.3(0.6,8.9)$ & 0.14 \\
\hline Visual constriction $n(\%)$ & $11(45.8)$ & $11(45.8)$ & $7(41.2)$ & $13(43.3)$ & \\
\hline PORs and 95\% CIs & 1 & $1.0(0.3,3.5)$ & $0.5(0.1,2)$ & $1.1(0.3,3.6)$ & 0.89 \\
\hline Hearing impairment $n(\%)$ & $16(72.7)$ & $19(86.4)$ & $15(78.9)$ & $20(64.5)$ & \\
\hline PORs and 95\% CIs & 1 & $2.6(0.5,13.2)$ & $1.1(0.2,5.1)$ & $0.6(0.1,2.2)$ & 0.25 \\
\hline Speech disturbance $n(\%)$ & $3(13)$ & $4(16.7)$ & $4(23.5)$ & $8(25)$ & \\
\hline PORs and 95\% CIs & 1 & $1.2(0.2,6.9)$ & $1.4(0.2,8.4)$ & $1.8(0.4,8.8)$ & 0.45 \\
\hline Disequilibrium $n(\%)$ & $20(83.3)$ & $21(87.5)$ & $16(80)$ & $31(91.2)$ & \\
\hline PORs and 95\% CIs & 1 & $1.4(0.3,7.1)$ & $0.7(0.1,3.4)$ & $1.9(0.3,10)$ & 0.66 \\
\hline
\end{tabular}

${ }^{*}$ Prevalence odds ratios were estimated using $0-20 \mathrm{ppm}$ as a reference and were adjusted for age and sex.

Abbreviations: C.I.: confidence interval; Dis.dom.bil.: distal dominant bilateral; NE: not estimatable; POR: prevalence odds ratio.

WHO limits could cause neurologic signs, in particular, sensory disturbance, which is consistent with the view of the National Research Council (US) [23] and the previous studies conducted in Brazil [24] and Minamata [10].

The finding that the dose-response relationship was observed for perioral sensory disturbance (Table 3 ) was consistent with the previous study in Minamata [10]. The reason why the dose-response relationships were not observed for other neurological sings could be explained by the sampling process. It is likely that the subjects who did not have the neurological signs in the lower level of the mercury exposure did not consult the doctors, probably diminishing the doseresponse relationships.

There is a concern that the hair mercury level measured in June 1965 may not reflect the peak exposure of the subjects. However, the hair mercury concentration of the subjects was measured at the relatively early phase of the outbreak. In addition, all of the hair samples were collected before the restriction of fishing; thus, the subjects were considered to be consuming the contaminated fish (at that time) and their hair mercury values were thought to be close to the peak exposure value. Thus, such a concern would not invalidate our result.

In the present study, a sensory disturbance of the bilateral distal extremities was most frequently detected (95.1\%), followed by disequilibrium ( $86.3 \%$ ), hearing impairment $(75.5 \%)$, and ataxia $(70.9 \%)$. Half of the subjects had sensory disturbance of the perioral area $(57.3 \%)$ and visual constriction $(44.2 \%)$. This tendency that the sensory disturbance was the most prevalent sign is consistent with the previous studies in Niigata [25] and Minamata [4] which examined the prevalence of the neurological signs among the exposed subjects.

The possible limitation of the present study is that there were three different methods for hair mercury measurement.
Hoshino et al. [26] measured total mercury content in hair samples from 3 Niigata Minamata disease patients and their 17 family members by using two techniques (the Neutron Activation Analysis and the Dithizone Method) and showed that the values from the two methods were similar. Moreover, Tsubaki [14] measured same samples by using the Dithizone Method and Atomic Absorption Analysis, then they showed that the values were the same between the two methods. Therefore, the different methods for hair mercury measurement would not explain the present results. Moreover, restricting the subjects whose hair mercury concentration was measured by the Dithizone Method did not alter the results in the sensitivity analysis.

As mentioned, another limitation is the sampling process of the present study. We could not obtain the information about health status of the 1277 persons who did not consult the doctors. This may affect the dose-response relationships and the obtained prevalence of the neurological signs in each exposure category. However, this limitation does not affect the present finding that there were subjects with the neurological signs related to $\mathrm{MeHg}$ poisoning in the exposure category of hair mercury levels less than $50 \mu \mathrm{g} / \mathrm{g}$.

\section{Conclusions}

The present study, conducted in Niigata Japan, showed that the subjects with the neurological signs related to $\mathrm{MeHg}$ poisoning had hair mercury levels less than $50 \mu \mathrm{g} / \mathrm{g}$ and suggested the possibility that long-term exposure to $\mathrm{MeHg}$ at levels below the current WHO limits could cause neurologic signs, in particular, sensory disturbance. Among the neurological signs, sensory disturbances of bilateral extremities were the most common. These findings may provide additional evidence for $\mathrm{MeHg}$ toxicity from contaminated seafood intake. 


\section{Ethical Approval}

This study was approved by the ethics committee of Niigata Seiryo University.

\section{Conflict of Interests}

The authors declared that they have no conflict of interests.

\section{Acknowledgments}

The authors would like to appreciate the contributions of the late professor Kenichi Shirakawa. The authors are truly grateful to Professor Gray J. Myers from the University of Rochester, Rochester, New York for his advice and editorial assistance. The study was conducted without any specific funding. This research was carried out at Kido Hospital.

\section{References}

[1] F. Bakir, S. F. Damluji, L. Amin-Zaki et al., "Methyl mercury Poisoning in Iraq," Science, vol. 181, pp. 230-241, 1973.

[2] M. Harada, "Minamata disease: methylmercury poisoning in Japan caused by environmental pollution," Critical Reviews in Toxicology, vol. 25, no. 1, pp. 1-24, 1995.

[3] T. Tsubaki, "Clinical epidemiology about niigata minamata disease," in Minamata Disease, Rresearches during 20 Years and the Problems at Present, S. Arima, Ed., pp. 291-300, Seirinsha, Tokyo, Japan, 1979.

[4] H. Tokuomi, "Clinical investigation on minamata disease. Minamata disease in human adult," in Minamata Disease, Study Group of Minamata Disease, Ed., pp. 48-81, Kumamoto University, Kumamoto, Japan, 1968.

[5] Ministry of Health and Welfare, "Research on diagnosis of the mercury poisoning," in Special Research Report on Organic Mercury poisoning in Niigata, pp. 3-24, Ministry of Health and Welfare, Tokyo, Japan, 1967.

[6] T. Tsubaki, "Organic mercurial poisoning along the River Agano,” Internal Medicine, vol. 21, no. 5, pp. 871-875, 1968 (Japanese).

[7] Ministry of Health and Welfare, "Epidemiological research on the mercury poisoning," in Special Research Report on Organic Mercury Poisoning in Niigata, p. 58, Ministry of Health and Welfare, Tokyo, Japan, 1967.

[8] World Hearth Organization, Environmental Health Criteria 1: Mercury, World Health Organization, gneva, Switzerland, 1976.

[9] World Hearth Organization, Environmental Health Criteria: 101. Methyl Mercury, World Health Organization, Geneva, Switzerland, 1990.

[10] T. Yorifuji, T. Tsuda, S. Takao, E. Suzuki, and M. Harada, “Total mercury content in hair and neurologic signs: historic data from minamata," Epidemiology, vol. 20, no. 2, pp. 188-193, 2009.

[11] T. Tsubaki, "The follow up of Niigata Minamata Disease," Science, vol. 42, pp. 526-531, 1972 (Japanese).

[12] T. Tsubaki, "Methyl mercury poisoning along the Agano River, researches by Niigata University," Clinical Neurology, vol. 8, pp. 511-520, 1968.

[13] T. W. Clarkson, L. Magos, and G. J. Myers, "The toxicology of mercury-current exposures and clinical manifestations,"
New England Journal of Medicine, vol. 349, no. 18, pp. 17311737, 2003.

[14] T. Tsubaki, K. Hirota, K. Shirakawa, K. Kondo, and T. Sato, "Clinical, epidemiological and toxicological studies on methyl mercury poisoning," in Proceedings of the 1st International Congress on Toxicology, G. L. Plaa and W. A. M. Duncan, Eds., pp. 339-357, Academic Press, New York, NY, USA.

[15] K. Kondo, "Incidence of Minamata disease in communities along the Agano river, Niigata, Japan-patterns of the exposure and official diagnosis of patients," Nihon Eiseigaku Zasshi, vol. 51, no. 2, pp. 599-611, 1996 (Japanese).

[16] The Committee on Reseach Human Right in The Japanese Society of Psychiatry and Neurology, "An opinion on the criteria on acquired Minamata disease," Psychiatria et Neurologia Japonica, vol. 100, pp. 765-790, 1998 (Japanese).

[17] T. Yorifuji, T. Tsuda, S. Inoue, S. Soshi Takao, M. Harada, and I. Kawachi, "Critical Appraisal of the 1977 Diagnostic Criteria for Minamata Disease," Archives of Environmental and Occupational Health. In press.

[18] T. Ninomiya, H. Ohmori, K. Hashimoto, K. Tsuruta, and S. Ekino, "Expansion of methylmercury poisoning outside of Minamata: an epidemiological study on chronic methylmercury poisoning outside of Minamata," Environmental Research, vol. 70, no. 1, pp. 47-50, 1995.

[19] T. Fujino, "A clinical and epidemiological study regarding effects of methylmercury exposure in island-second report," Kumamoto Igakukai Zassi, vol. 51, pp. 90-147, 1977 (Japanese).

[20] T. Kumamoto, Reserch Regarding the Effect of Aging on Neurological Disorders, Japan Public Health Association, Tokyo, Japan, 1993.

[21] M. Nou, Effects of Aging on Clinical Features of Minamata Disease Patients, Japan Public Health Association, 1993.

[22] H. Tokuomi, T. Okajima, S. Kawasaki, R. Inoue, and Y. Kinoshita, "Problems of Minamata disease from the perspective of elder's health checkup," Environmental Health Report, vol. 37, pp. 149-156, 1976 (Japanese).

[23] National Research Council, Toxicological Effect of Methylmercury, National Academy Press, Washington, DC, USA, 2000.

[24] E. M. Yokoo, J. G. Valente, L. Grattan, S. L. Schmidt, I. Platt, and E. K. Silbergeld, "Low level methylmercury exposure affects neuropsychological function in adults," Environmental Health, vol. 2, article 1, pp. 1-11, 2003.

[25] T. Tsubaki, K. Hirota, and K. Shirakawa, "Clinical symptoms and hair mercury content on niigata minamata disease," Environmental Health Report, vol. 37, pp. 118-122, 1976 (Japanese).

[26] O. Hoshino, K. Tanzawa, M. Terao, and T. Ukita, "Quantitative determination of mercury in hair by activation analysis," Eiseikagaku, vol. 12, pp. 94-99, 1966 (Japanese). 

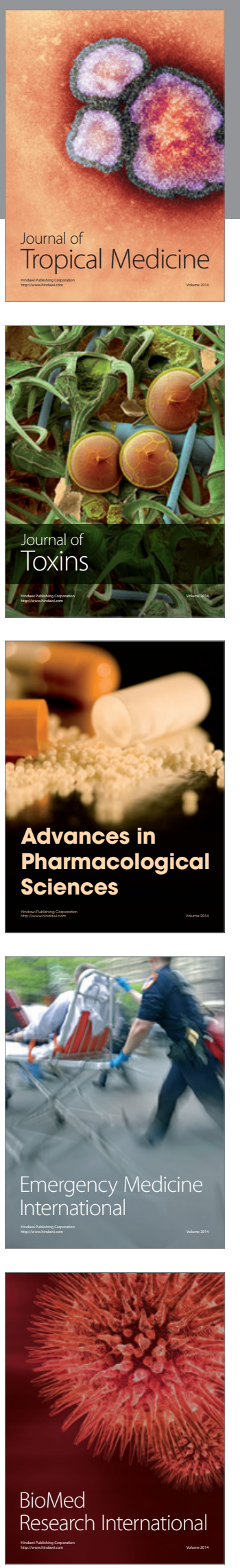
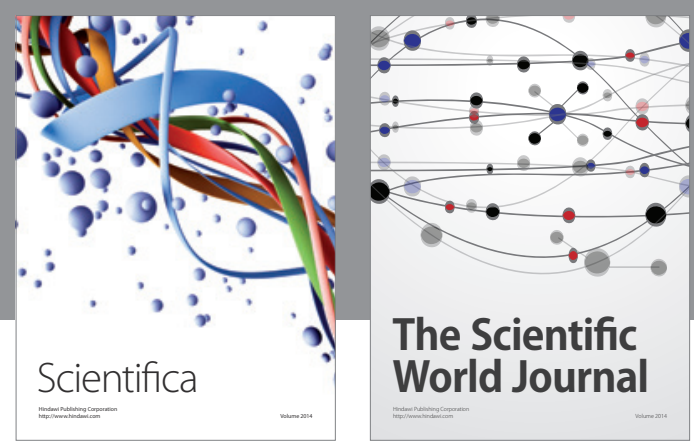

The Scientific World Journal
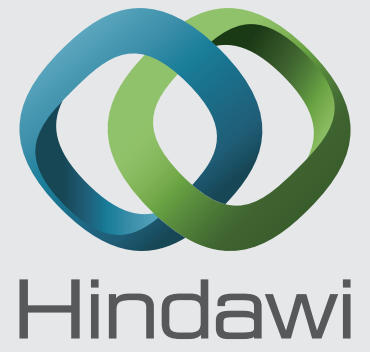

Submit your manuscripts at

http://www.hindawi.com
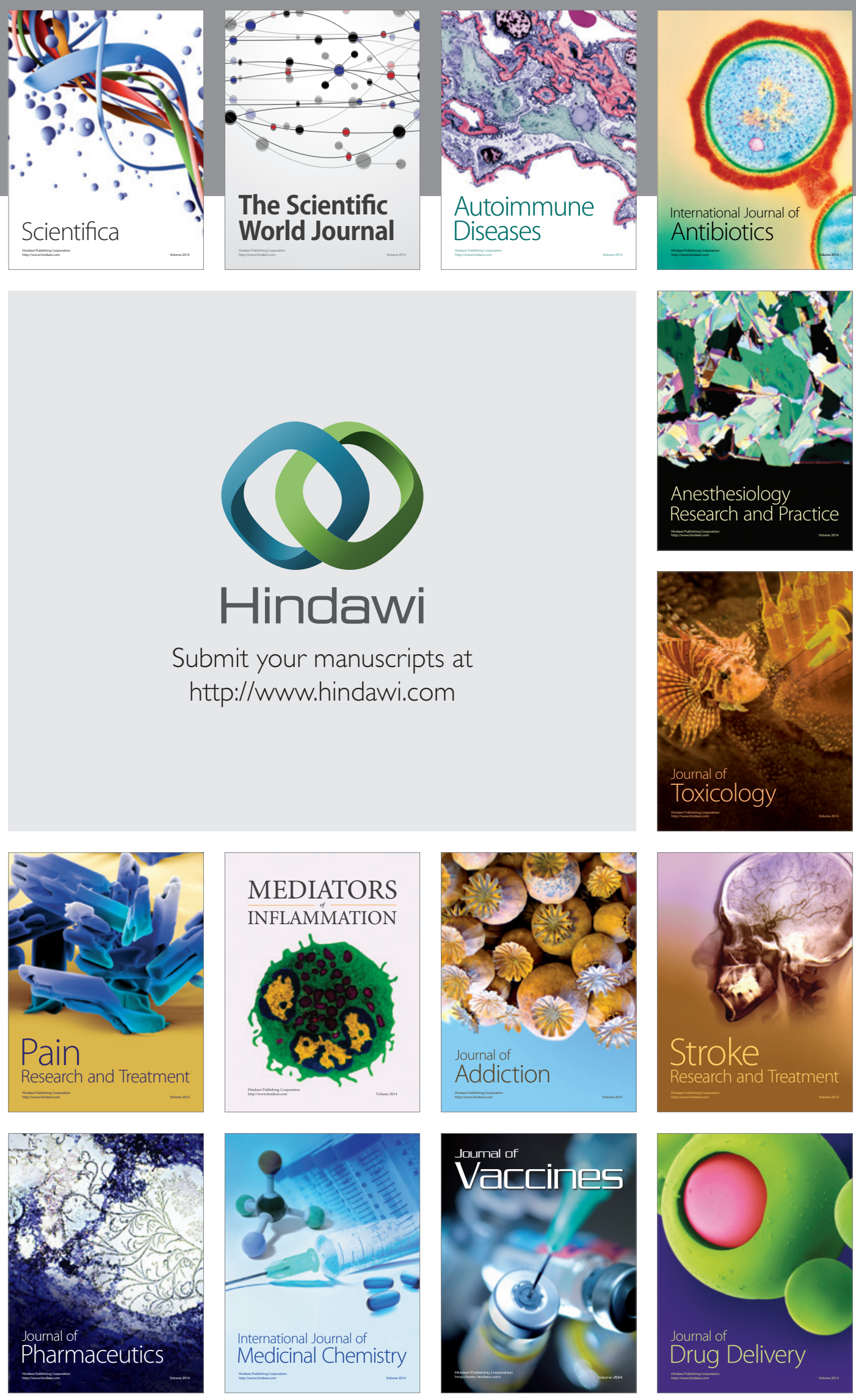